\title{
Living in "Cold Spot" Communities Is Associated with Poor Health and Health Quality
}

\author{
Winston Liaw, MD, MPH, Alex H. Krist, MD, MPH, Sebastian T. Tong, MD, MPH, \\ Roy Sabo, PhD, Camille Hochbeimer, Jennifer Rankin, PhD, MPH, MS, MHA, \\ David Grolling, MPS, Jene Grandmont, MA, and Andrew W. Bazemore, MD, MPH
}

Purpose: Little is known about incorporating community data into clinical care. This study sought to understand the clinical associations of cold spots (census tracts with worse income, education, and composite deprivation).

Methods: Across 12 practices, we assessed the relationship between cold spots and clinical outcomes (obesity, uncontrolled diabetes, pneumonia vaccination, cancer screening - colon, cervical, and prostate-and aspirin chemoprophylaxis) for 152,962 patients. We geocoded and linked addresses to census tracts and assessed, at the census tract level, the percentage earning less than $200 \%$ of the Federal Poverty Level, without high school diplomas, and the social deprivation index (SDI). We labeled those census tracts in the worst quartiles as cold spots and conducted bivariate and logistic regression.

Results: There was a 10-fold difference in the proportion of patients in cold spots between the highest (29.1\%) and lowest practices (2.6\%). Except for aspirin, all outcomes were influenced by cold spots. Fifteen percent of low-education cold-spot patients had uncontrolled diabetes compared with $13 \%$ of noncold-spot patients $(P<.05)$. In regression, those in poverty, low education, and SDI cold spots were less likely to receive colon cancer screening (odds ratio $[\mathrm{CI}], 0.88[0.83-0.93], 0.87[0.82-$ $0.92]$, and 0.89 [0.83-0.95], respectively) although cold-spot patients were more likely to receive cervical cancer screening.

Conclusion: Living in cold spots is associated with worse chronic conditions and quality for some screening tests. Practices can use neighborhood data to allocate resources and identify those at risk for poor outcomes. (J Am Board Fam Med 2018;31:342-350.)

Keywords: Cancer Screening, Censuses, Health Resources, Health Services, Health Status, Logistic Regression, Poverty

The United States suffers from both poor health outcomes and wide disparities. ${ }^{1-3}$ One strategy for improving national health indicators is addressing social determinants of health $(\mathrm{SDH})^{4}$, or the conditions in which people are born, grow, live, work, and age. ${ }^{5}$ Proponents point to the growing body of evidence that SDH impact health more than medical care. ${ }^{5-10}$

This article was externally peer reviewed.

Submitted 26 October 2017; revised 9 January 2018; accepted 12 January 2018.

From the Robert Graham Center, Washington, DC (WL, AWB); Virginia Commonwealth University, Richmond, VA (AHK, STT, RS, CH); HealthLandscape, Cincinnati, OH (JR, DG, JG); McGovern Medical School, University of Texas Health Science Center at Houston (UTHealth), Houston, TX (WL).
Researchers have highlighted the complex pathways linking social determinants to health. For example, education empowers individuals to make healthy choices, leading to higher earnings, better access to care, and ultimately, lower mortality. ${ }^{11-13}$ Similarly, income and affluence affect health. ${ }^{6,10,14}$ Affluence tracks with other, favorable neighborhood characteristics such as low

Funding: UL1TR000058 from the National Center for Advancing Translational Sciences and the CCTR Endowment Fund of Virginia Commonwealth University.

Prior presentations: North American Primary Care Research Conference Annual Meeting, November 2016, Colorado Springs, CO.

Conflict of interest: none declared.

Corresponding author: Winston Liaw, MD, 6431 Fannin, JJL308S, Houston, Texas 77030 (E-mail: winston.liaw@ uth.tmc.edu). 
crime, healthy food, places to exercise, and clean air. ${ }^{15-19}$ Researchers such as Krieger et al ${ }^{20}$ have added to this evidence base by quantifying the relationship between health outcomes and areabased socioeconomic measures across a wide spectrum of geographic units.

While the work of Krieger et $\mathrm{al}^{20}$ elucidates the relationship between ecologic socioeconomic measures and health outcomes, there is growing recognition of the effect of neighborhoods on individual health. Researchers have examined the contextual effects of living in deprived communities and hypothesized that these neighborhoods have worse physical environments (such as poor water quality and environmental pollution) and inferior access to goods and services. ${ }^{21}$ Neighborhood deprivation has been tied to an individual's risk for child abuse, low birth weight, adolescent pregnancy, childhood injury, and firearm injury. ${ }^{22-24}$ From an economic perspective, Chetty et $\mathrm{al}^{25}$ found that childhood neighborhood poverty can have long-lasting detrimental effects on an individual's adult income. Less has been published on the relationship between neighborhood deprivation and the quality of care delivered. Although one study failed to find an association, others have documented in international settings that living in deprived neighborhoods is associated with lower rates of breast, colon, and cervical cancer screening. ${ }^{26-28}$

To encourage providers to address SDHs, payers are transitioning from volume to value-based payment through programs such as accountable care organizations and accountable health communities and adjusting payment and measurement for patient social risks. ${ }^{29-31}$ Modern generalists, such as Jack Westfall, are seizing on this pivot to promote greater recognition of SDH. In his 2013 commentary, Dr. Westfall proposed cold spotting-identifying those communities that lack essential opportunities for health-and addressing those needs with community-level interventions. $^{32}$ Our goal was to operationalize cold spots using electronic health record (EHR) data and determine whether patients coming from communities with lower income and education and greater composite deprivation within a health system (cold spots) have worse clinical outcomes, such as receiving inadequate care and worse chronic disease control.

\section{Methods}

\section{Design}

In this cross-sectional study of 12 practices in the Virginia Ambulatory Care Outcomes Research Network, we assessed the relationship between living in cold spots and quality measures. The practices are located within a 45 -mile radius and care for patients in Fairfax, Loudoun, Prince William, Fauquier, and Arlington counties, which are among the most affluent in the United States. ${ }^{33}$ The practices operate independently for clinical, staffing, and business activities but work collectively for information technology (eg, a shared EHR) and population health (eg, an ACO and a shared care management team). All practices are private, and one operates a family medicine residency program. We included in our analysis all unique patients, between the ages of 18 and 75 years, with an address in Virginia, seen at the study practices between January 1, 2012 and December 31, 2014.

\section{Data Sources}

To identify cold spots, we used the 2010 American Community Survey for poverty, education, and the social deprivation index (SDI) and the Virginia Department of Health, Division of Vital Records data for life expectancy. To measure the quality of care delivered to patients, we used data from the practices' EHR for the aforementioned timeframe.

\section{Variables}

Using these data sources, we connected census tracts to their commensurate community characteristics. We assessed poverty by calculating the percentage of the census tract earning less than $200 \%$ of the federal poverty level (FPL) and education by assessing the percentage without a high school diploma or passing the General Education Development test. The SDI is a composite measure of social and material deprivation at the census tract level, encompassing education, crowding, transportation, employment, poverty, housing, and family structure (single parent). ${ }^{34}$ SDI has been validated against mortality, diabetes, and infant mortality and is normally distributed with a score from 0 to 100 , where higher numbers suggest higher deprivation.

Using methods similar to our previous work, we assessed individual patient-level quality measures (pneumonia vaccination, colon cancer screening, cervical cancer screening, prostate cancer screen- 
ing, and aspirin for cardiovascular disease) and 2 chronic conditions (obesity and uncontrolled diabetes). ${ }^{19} \mathrm{We}$ assessed pneumonia vaccination by determining whether those 65 years or older had 1 dose of the 23- or 13-valent pneumococcal vaccine, colorectal cancer screening by determining whether those aged 50 to 75 years had a colonoscopy within the past 10 years or a fecal occult blood test within the past year, cervical cancer screening by determining whether women aged 21 to 65 years had a Papanicolaou smear within the past 3 years or those aged 30 to 65 years had a Papanicolaou smear and human papilloma virus testing within the past 5 years, prostate cancer screening by whether men aged 55 to 70 years had a prostate-specific antigen performed within the past 2 years (excluding those with personal or family histories of prostate cancer, and African Americans), and aspirin use by determining whether those with a diagnosis of cardiovascular disease had aspirin prescribed. Obesity was defined as those with a body mass index of 30 or more. Uncontrolled diabetes was defined as those with a hemoglobin A1c of $9 \%$ or more. These were dichotomous variables assessing whether each patient had the preventive measure or chronic condition.

We used the patient's age at the most recent visit. Sex, race, and ethnicity were patient reported. Race had 5 categories (Asian, Black/African American, White, Declined, and Other) and ethnicity had 3 categories (Hispanic or Latino, Not Hispanic or Latino, or Unknown).

\section{Analytic Plan}

Using Esri ArcMap 10.3.1. (Redlands CA), we geocoded addresses for patients in our sample and identified the corresponding 2010 census tract for each address. We linked each census tract with its commensurate level of poverty, education, and social deprivation. For practice-level service areas, we included census tracts, in Virginia, with at least 5 patients.

\section{Cold-Spot Designation}

Because we lacked a well-established method for identifying cold spots, we defined cold spots at the census tract level using 3 different methods. In the first method (henceforth the Percentile Approach), we identified those census tracts in the highest quartiles for poverty, low education, and SDI compared with all other census tracts represented in the practices' $100 \%$ service area. The second method (henceforth the National Standard Approach) identified census tracts that have specific values greater than meaningful values published in the literature. We identified census tracts with $\geq 20 \%$ of the census tract earning less than $200 \%$ of the FPL, $\geq 40 \%$ with less than a high school education, or $\geq 70$ SDI score. Krieger et $\mathrm{al}^{20}$ documented the relationship between community measures and health outcomes, demonstrating that these measures are sensitive to expected gradients in health. We used Krieger's cut-offs for the worst census tracts for poverty and education and a comparable cutoff for SDI ( $\geq 70)$. The third method (henceforth the Empirical Approach) uses a grid search of cutoff values (in increments of 1\%) for classifying census tracts as cold spots. These census tract classifications are then regressed against life expectancy at the census tract level, with the cutoff that yields the lowest value of Akaiki's Information Criterion selected for that cold spot.

Using SAS (Cary, NC), we calculated descriptive statistics regarding cold-spot definitions, across the practice locations. Generalized linear mixed models were used to estimate odds ratios between cold-spot designation and quality measures (pneumonia, obesity, hemoglobin A1c, colon cancer, cervical cancer, and aspirin); these analyses were conducted separately for each coldspot indicator (education, poverty, SDI). Quality measures were included as binary outcomes of whether a subject was screened for or meets the stated condition and were modeled against a fixed effect for cold spot designation (Yes/No) for that patient's practice. A practice-level random effect was included to account for the possibility of practice-level heterogeneity in quality measure proportions. Odds ratios (and 95\% CIs) were calculated as the ratio of the odds for being screened or at risk in a cold spot over the odds for being screened or at risk in a noncold spot. $\mathrm{Pa}$ tient characteristics (age, sex, and race/ethnicity) were included as fixed effects. These analyses were also conducted for each of the 3 cold-spot designation methods described above (Percentile, National Standard, Empirical).

The Virginia Commonwealth University Institutional Review Board approved this protocol. 
Table 1. Average Census Tract Poverty, Low Education, and Composite Social Deprivation, by Practice Site Service Areas

\begin{tabular}{cccccc}
\hline & & & \multicolumn{2}{c}{$\begin{array}{c}\text { Average Community Characteristics, by 100\% Practice Service } \\
\text { Area }\end{array}$} \\
\cline { 3 - 5 } Practice Code & $\begin{array}{c}\text { Number of } \\
\text { Patients }\end{array}$ & $\begin{array}{c}\text { Percentage of Overall } \\
\text { System }\end{array}$ & $\begin{array}{c}\text { Low Education, } \\
\% \text { (SD) }\end{array}$ & $\begin{array}{c}\text { Social Deprivation } \\
\text { Index (SD) }\end{array}$ \\
\hline 03 & 17,468 & $11.4 \%$ & $15.9 \%(12.1)$ & $10.6 \%(6.9)$ & $28.5(27.1)$ \\
07 & 5,742 & $3.8 \%$ & $14.6 \%(8.9)$ & $8.0 \%(5.2)$ & $26.5(20.4)$ \\
12 & 1,885 & $1.2 \%$ & $14.3 \%(8.9)$ & $8.1 \%(6.5)$ & $27.5(21.7)$ \\
10 & 24,618 & $16.1 \%$ & $11.5 \%(9.8)$ & $7.0 \%(7.2)$ & $21.9(20.5)$ \\
09 & 9,239 & $6.0 \%$ & $11.4 \%(9.6)$ & $6.8 \%(5.6)$ & $20.4(20.7)$ \\
06 & 13,191 & $8.6 \%$ & $11.3 \%(9.9)$ & $5.7 \%(6.4)$ & $21.5(21.8)$ \\
01 & 29,074 & $19.0 \%$ & $11.3 \%(8.8)$ & $5.7 \%(5.2)$ & $19.0(19.3)$ \\
02 & 21,174 & $13.9 \%$ & $10.6 \%(7.7)$ & $6.1 \%(5.7)$ & $19.7(18.4)$ \\
11 & 3,299 & $2.2 \%$ & $9.4 \%(8.4)$ & $5.0 \%(6.0)$ & $16.2(20.5)$ \\
08 & 7,843 & $5.1 \%$ & $7.1 \%(6.9)$ & $4.4 \%(4.1)$ & $11.2(14.3)$ \\
04 & 12,733 & $8.3 \%$ & $6.8 \%(6.5)$ & $4.2 \%(4.2)$ & $11.8(14.7)$ \\
05 & 6,696 & $6.0 \%(6.3)$ & $3.8 \%(3.8)$ & $10.8(13.5)$ \\
\hline Overall system & 152,962 & $100.0 \%$ & $11.0 \%(9.4)$ & $6.4 \%(6.1)$ & $19.9(20.7)$ \\
\hline
\end{tabular}

For practice-level service areas, we included census tracts, in Virginia, with at least 5 patients. Cold spots are defined as those census tracts in the highest quartiles for poverty, low education, and composite social deprivation. Poverty is measured by the percentage earning less than $200 \%$ of the federal poverty level. Low education measured by the percentage without a high school diploma or General Education Development. The Social Deprivation Index is a composite measure of community material and social deprivation and is a score from 0 to 100 .

$\mathrm{SD}$, standard deviation.

\section{Results}

\section{Practice Demographics}

Our sample included 152,962 unique patients, living in 973 census tracts. The number of census tracts per practice ranged from 4 to 264 . When looking at the proportions of patients in each practice from cold spots and their relationships to quality, the results were similar across the 3 cold-spot designation methods. Due to its ease of use relative to the other methods, we only present results from the Percentile Approach. Despite the relative affluence of northern Virginia, we observed variation in community measures across the census tracts represented within practices (Table 1). For example, the average percentage earning less than $200 \%$ of the FPL within Practice 05's service area census tracts was $6.0 \%$ while this figure was nearly 3 -fold higher for Practice 03 (15.9\%). We observed similar trends for the percentage with low education and the SDI.

\section{Cold Spots}

Using the Percentile Approach, we used the following cutoffs (highest quartiles) for poverty, low education, and SDI: $23.4 \%, 12.8 \%$, and 44 , respec- tively (Table 2). Thus, patients living in census tracts with community characteristics at or above these thresholds were classified as living in cold spots. Overall, 19,653 (12.8\%) patients live in a poverty cold spot. When looking at the proportion of practice patients in cold spots, the degree of variation across practices is magnified. For example, we observed a 10-fold difference in the proportion of patients in cold spots between the highest $(29.1 \%$ of Practice 03 's patients live in a poverty cold spot) and lowest practices (2.6\% for Practice $05)$. These figures and trends were similar for low education and SDI. Across poverty and low education, the same 3 practices $(03,10$, and 12$)$ had the highest percentages of patients in cold spots while the same 3 practices $(08,04,05)$ had the lowest percentages.

\section{Associations with Health Outcomes and Quality}

With the exception of aspirin chemoprevention, all preventive and chronic care measures were influenced by whether a patient lived in a cold spot (Table 3). Associations most consistently occurred for the low-education cold-spot designation, although not all in the anticipated directions. $\mathrm{Pa}$ - 
Table 2. Patients Living in Highest Poverty, Low Education, and Composite Social Deprivation Quartiles, by Practice

\begin{tabular}{|c|c|c|c|c|c|c|}
\hline \multirow[b]{2}{*}{ Practice Code } & \multicolumn{6}{|c|}{ Number and Percentage of Patients Living in Cold Spots } \\
\hline & $\begin{array}{l}\text { Number of Patients } \\
\text { in Poverty Cold } \\
\text { Spots }\end{array}$ & $\begin{array}{l}\text { Percentage } \\
\text { of Practice }\end{array}$ & $\begin{array}{l}\text { Number of Patients } \\
\text { Low Education } \\
\text { Cold Spots }\end{array}$ & $\begin{array}{l}\text { Percentage } \\
\text { of Practice }\end{array}$ & $\begin{array}{l}\text { Number of Patients in } \\
\text { Social Deprivation } \\
\text { Index Cold Spots }\end{array}$ & $\begin{array}{l}\text { Percentage } \\
\text { of Practice }\end{array}$ \\
\hline 03 & 5,082 & $29.1 \%$ & 6,328 & $36.2 \%$ & 5,645 & $32.3 \%$ \\
\hline 10 & 4,071 & $16.5 \%$ & 4,308 & $17.5 \%$ & 3,552 & $14.4 \%$ \\
\hline 12 & 294 & $15.6 \%$ & 350 & $18.6 \%$ & 338 & $17.9 \%$ \\
\hline 06 & 2,031 & $15.4 \%$ & 1,761 & $13.4 \%$ & 2,000 & $15.2 \%$ \\
\hline 09 & 1,346 & $14.6 \%$ & 1,167 & $12.6 \%$ & 1,278 & $13.8 \%$ \\
\hline 01 & 3,407 & $11.7 \%$ & 2,639 & $9.1 \%$ & 2,938 & $10.1 \%$ \\
\hline 07 & 652 & $11.4 \%$ & 622 & $10.8 \%$ & 1,270 & $22.1 \%$ \\
\hline 11 & 324 & $9.8 \%$ & 345 & $10.5 \%$ & 311 & $9.4 \%$ \\
\hline 02 & 1,488 & $7.0 \%$ & 2,317 & $10.9 \%$ & 2,065 & $9.8 \%$ \\
\hline 08 & 419 & $5.3 \%$ & 332 & $4.2 \%$ & 342 & $4.4 \%$ \\
\hline 04 & 367 & $2.9 \%$ & 473 & $3.7 \%$ & 580 & $4.6 \%$ \\
\hline 05 & 172 & $2.6 \%$ & 201 & $3.0 \%$ & 246 & $3.7 \%$ \\
\hline Overall system & 19,653 & $12.8 \%$ & 20,843 & $13.6 \%$ & 20,565 & $13.4 \%$ \\
\hline
\end{tabular}

For practice-level service areas, we included census tracts, in Virginia, with at least 5 patients. Cold spots are defined as those census tracts in the highest quartiles for poverty, low education, and composite social deprivation. Poverty is measured by the percentage earning less than $200 \%$ of the federal poverty level. Low education measured by the percentage without a high school diploma or General Education Development. The Social Deprivation Index is a composite measure of community material and social deprivation and is a score from 0 to 100 .

tients were more likely to be obese, have uncontrolled diabetes, and not receive colon and prostate cancer screening if they lived in a low-education cold spot. Conversely, patients were more likely to get a pneumonia vaccine and get screened for cervical cancer if they lived in a low-education cold spot.

After controlling for age, sex, race, and ethnicity, we found that poverty and SDI cold-spot patients had higher odds of obesity, lower odds of receiving colon cancer screening, and higher odds of receiving cervical cancer screening (Table 4).

\section{Discussion}

Across these practices, there is substantial variation in the proportion of patients living in communities with higher poverty, lower education, and greater social deprivation even in an affluent region. This is important because living in a cold spot is associated with worse chronic care and quality, such as higher obesity and lower colon cancer screening rates. However, the relationship between quality and living in a cold spot is complex, and some quality measures seem better for patients living in cold spots, such as cervical cancer screening.
Our US-based, EHR-derived findings support the results of others that neighborhood deprivation affects screening, diabetes, and obesity though we were unable to find other studies that assessed diabetes control. ${ }^{35-41}$ This reinforces the notion that deprived neighborhoods have distinct effects on health and care delivery and underscores the importance of using geography as a lens through which to view population health. Although imperfect, we provide a reproducible, practical, and feasible method for integrating community data into EHRs.

Our findings also highlight that the effect of neighborhood deprivation using this method is nuanced. Counter to what is expected, we observed that patients in cold spots were more likely to receive cervical cancer screening and pneumonia vaccines (for educational cold spots). To reduce disparities, researchers, providers, and policy makers may have developed programs that target underserved populations and minorities in this community. Although our findings may truly reflect better care for patients in cold spots, another explanation is that patients living in noncold spots are more likely to also see other care providers (gynecologists for Papanicolaou smears or pharmacists 
Table 3. Quality of Chronic and Preventive Care by Cold-Spot Designation

\begin{tabular}{|c|c|c|c|c|c|c|}
\hline & \multicolumn{6}{|c|}{ Cold-Spot Designation } \\
\hline & \multicolumn{2}{|c|}{ Poverty } & \multicolumn{2}{|c|}{ Low Education } & \multicolumn{2}{|c|}{ Social Deprivation Index } \\
\hline & \multicolumn{6}{|c|}{ Percentage with the Chronic Condition or Receiving the Preventive Measure } \\
\hline & Cold Spot & Noncold Spot & Cold Spot & Noncold Spot & Cold Spot & Noncold Spot \\
\hline \multicolumn{7}{|l|}{ Chronic conditions } \\
\hline Obesity & $34 \% *$ & $28 \%$ & $37 \% *$ & $28 \%$ & $35 \%$ * & $28 \%$ \\
\hline $\begin{array}{l}\text { Uncontrolled } \\
\text { diabetes }\end{array}$ & $14 \%$ & $12 \%$ & $15 \%$ * & $13 \%$ & $15 \%$ * & $13 \%$ \\
\hline \multicolumn{7}{|c|}{ Preventive measures } \\
\hline Prostate cancer & $45 \%$ * & $50 \%$ & $45 \% *$ & $50 \%$ & $47 \%$ & $49 \%$ \\
\hline $\begin{array}{l}\text { Pneumonia } \\
\text { vaccination }\end{array}$ & $23 \%$ & $23 \%$ & $25 \%$ * & $23 \%$ & $23 \%$ & $23 \%$ \\
\hline $\begin{array}{l}\text { Colon cancer } \\
\text { screening }\end{array}$ & $30 \% *$ & $32 \%$ & $29 \% *$ & $32 \%$ & $30 \% *$ & $32 \%$ \\
\hline $\begin{array}{l}\text { Cervical cancer } \\
\text { screening }\end{array}$ & $16 \%$ * & $15 \%$ & $17 \%$ * & $15 \%$ & $17 \%$ * & $15 \%$ \\
\hline Aspirin & $44 \%$ & $43 \%$ & $44 \%$ & $43 \%$ & $44 \%$ & $43 \%$ \\
\hline
\end{tabular}

*Percentages are significantly different $(P<.05)$.

Cold spots are defined as those census tracts in the highest quartiles for poverty, low education, and composite social deprivation. Poverty is measured by the percentage earning less than $200 \%$ of the federal poverty level. Low education measured by the percentage without a high school diploma or General Education Development. The Social Deprivation Index is a composite measure of community material and social deprivation and is a score from 0 to 100 .

Obesity was defined as those with a body mass index of $30 \mathrm{~kg} / \mathrm{m}^{2}$ or more.

Uncontrolled diabetes was defined as those with a hemoglobin A1c of 9 or more.

We assessed pneumonia vaccination by determining whether those 65 years or older had one dose of the 23- or 13-valent pneumococcal vaccine, colorectal cancer screening by determining whether those aged 50 to 75 years had a colonoscopy within the past 10 years or a fecal occult blood test within the past year, cervical cancer screening by determining whether those aged 21 to 65 years had a pap smear within the past 3 years or those aged 30 to 65 years had a pap smear and human papilloma virus testing within the past 5 years, prostate cancer screening by whether men aged 55 to 70 years had a prostate-specific antigen performed within the past 2 years (excluding those with personal or family histories of prostate cancer, and African Americans), and aspirin use by determining whether those with a diagnosis of heart disease, congestive heart failure, or peripheral vascular disease had aspirin prescribed.

for immunizations) and care is incompletely documented in the EHR. Similarly, higher rates of prostate cancer screening in noncold spots may reflect worse care, if it is a symptom of overtesting or inadequate shared decision making.

Much work is needed to determine what primary care can do with this additional information. In an accompanying mixed methods study, we provided clinicians with information about patient neighborhoods and individual needs and found that having the information increased clinician awareness about social needs and the amount and type of patient education delivered. ${ }^{42}$ Others have outlined the specific questions and processes that should be used to standardize collection of individual social needs in primary care settings. ${ }^{43}$ At a system level, organizations are experimenting with novel methods for addressing social needs. CommunityRx combines e-prescribing and community engagement to connect patients with community re- sources, via the diagnoses generated in EHRs. ${ }^{44}$ Hennepin Health integrated a public health department, medical center, federally qualified health center, and health plan across payment, delivery, and data systems to better coordinate services and address SDH. ${ }^{45}$ Although these 2 organizations transformed care at great cost, practices can make meaningful changes on smaller scales. Using this method, health systems can measure the variation in their own communities, more efficiently distribute staff and resources, and target interventions. Practices can provide more proactive care and enhance quality improvement by using cold spots to identify those at risk for worse quality measures. Finally, those with community-engagement partners or expertise can fulfill Westfall's original vision of responding to cold spots with community approaches. Rather than address individuals, Westfall imagined communities of solution, where broad 
Table 4. Adjusted Odds Ratios for Quality of Chronic and Preventive Care by Cold Spot Designation

\begin{tabular}{|c|c|c|c|c|c|c|}
\hline & \multicolumn{6}{|c|}{ Cold Spot Designation } \\
\hline & \multicolumn{2}{|c|}{ Poverty } & \multicolumn{2}{|c|}{ Low Education } & \multicolumn{2}{|c|}{ Social Deprivation Index } \\
\hline & OR & $95 \% \mathrm{CI}$ & OR & $95 \% \mathrm{CI}$ & OR & $95 \% \mathrm{CI}$ \\
\hline \multicolumn{7}{|l|}{ Chronic conditions } \\
\hline Obesity & $1.33^{*}$ & $1.29-1.38$ & $1.58^{\star \dagger}$ & $1.53-1.63$ & $1.36^{*}$ & $1.31-1.41$ \\
\hline Uncontrolled diabetes & 1.06 & $0.89-1.26$ & 1.16 & $0.98-1.38$ & 1.12 & $0.93-1.35$ \\
\hline \multicolumn{7}{|l|}{ Preventive measures } \\
\hline Prostate cancer & $0.8^{*}$ & $0.71-0.90$ & $0.83^{*}$ & $0.73-0.92$ & 0.91 & $0.79-1.03$ \\
\hline Pneumonia vaccination & $1.13^{* \dagger}$ & $1.07-1.20$ & $1.24^{* \dagger}$ & $1.17-1.31$ & $1.15^{\text {*十 }}$ & $1.08-1.22$ \\
\hline $\begin{array}{l}\text { Colon cancer } \\
\text { screening }\end{array}$ & $0.88^{*}$ & $0.83-0.93$ & $0.87^{*}$ & $0.82-0.92$ & $0.89^{*}$ & $0.83-0.95$ \\
\hline $\begin{array}{l}\text { Cervical cancer } \\
\text { screening }\end{array}$ & $1.13^{*}$ & $1.07-1.19$ & $1.17^{*}$ & $1.11-1.23$ & $1.18^{*}$ & $1.11-1.24$ \\
\hline Aspirin & 1.13 & $0.92-1.38$ & 1.18 & $0.97-1.44$ & 1.18 & $0.95-1.47$ \\
\hline
\end{tabular}

CI, confidential interval; OR, odds ratio.

${ }^{*}$ ORs are significantly different from $1(P<.05)$.

${ }^{\dagger}$ The full multivariable model did not converge, so the practice random effect was excluded. Adjusted for age (estimates provided at age $=42.5$ years), gender, race, and ethnicity. Cold spots are defined as those census tracts in the highest quartiles for poverty, low education, and composite social deprivation. Poverty is measured by the percentage earning less than $200 \%$ of the federal poverty level. Low education is measured by the percentage without a high school diploma or General Education Development. The Social Deprivation Index is a composite measure of community material and social deprivation and is a score from 0 to 100 . Obesity was defined as those with a body mass index of 30 or more. Uncontrolled diabetes was defined as those with a hemoglobin A1c of 9 or more.

We assessed pneumonia vaccination by determining whether those 65 years or older had one dose of the 23- or 13-valent pneumococcal vaccine, colorectal cancer screening by determining whether those aged 50 to 75 year had a colonoscopy within the past 10 years or a fecal occult blood test within the past year, cervical cancer screening by determining whether those aged 21 to 65 had a pap smear within the past 3 years or those aged 30 to 65 had a pap smear human papilloma virus testing within the past 5 years, prostate cancer screening by whether men aged 55 to 70 had a prostate specific antigen performed within the past 2 years (excluding those with personal or family histories of prostate cancer, and African Americans), and aspirin use by determining whether those with a diagnosis of heart disease, congestive heart failure, or peripheral vascular disease had aspirin prescribed.

stakeholders are engaged to tackle systemic problems. ${ }^{32}$

Our study has several limitations. First, we used data from a highly affluent region; therefore, our results may not be generalizable to other communities or other health systems. It is possible that cold spots may be associated with variation in different quality measures and that the magnitude of differences may fluctuate. Second, there may be unmeasured community variables that account for the observed variation. Although the SDI encompasses 9 dimensions of deprivation, we were unable to control for every potential confounder. Finally, although we controlled for some individual characteristics, there were numerous individual variables not included in our model. For instance, we lacked data about the individual's social needs, measures of multimorbidity, insurance status, health literacy, and use of clinical services. We also lacked insight into how individuals communicated with clinicians, including the degree of language concordance and the quality of the communication.

In summary, we found substantial variation in deprivation across practices. This deprivation was associated with chronic disease and differences in quality. More studies are needed to explore what practices and clinicians should do in response to this information. Although we lack a full understanding regarding how this information should inform care, integrating community data and primary care EHRs may be an important strategy for improving population health and succeeding in a value based payment environment.

We thank Steven Woolf and Derek Chapman for providing Virginia life-expectancy data, Stephen Petterson for his assistance with the social deprivation index, and Bob Phillips for theoretical guidance.

To see this article online, please go to: http://jabfm.org/content/ 31/3/342.full. 


\section{References}

1. Case A, Deaton A. Rising morbidity and mortality in midlife among white non-Hispanic Americans in the 21st century. Proc Natl Acad Sci 2015;112: 15078-83.

2. Smedley BD, Stith AY, Nelson AR, eds. Unequal treatment: confronting racial and ethnic disparities in health care (full printed version). Washington, D.C.: National Academies Press; 2003.

3. Woolf SH, Aron L, eds. US health in international perspective: Shorter lives, poorer health. Washington D.C.: National Academies Press; 2013.

4. Committee on Integrating Primary Care and Public Health. Primary care and public health: Exploring integration to improve population health. Washington, D.C.: National Academy Press; 2012.

5. WHO Commission on Social Determinants of Health, World Health Organization, eds. Closing the gap in a generation: Health equity through action on the social determinants of health: Commission on social determinants of health final report. Geneva, Switzerland: World Health Organization, Commission on Social Determinants of Health; 2008.

6. Marmot MG, Shipley MJ, Rose G. Inequalities in death-Specific explanations of a general pattern? Lancet 1984;1:1003-6.

7. Link BG, Phelan J. Social conditions as fundamental causes of disease. J Health Soc Behav 1995;35:80.

8. McGinnis JM, Williams-Russo P, Knickman JR. The case for more active policy attention to health promotion. Health Aff (Millwood) 2002;21:78-93.

9. McGinnis JM, Foege WH. Actual causes of death in the United States. JAMA 1993;270:2207-12.

10. Berkman LF, Kawachi I. Social epidemiology. New York City, NY: Oxford University Press; 2000.

11. Zimmerman E, Woolf SH. Understanding the relationship between education and health. June 5, 2014. Available from: https://apha.confex.com/apha/142am/ webprogram/Handout/Paper315693/Final\%20BPHUnderstandingTheRelationship.pdf. Accessed March 10, 2017.

12. Woolf SH, Johnson RE, Phillips RL Jr, Philipsen M. Giving everyone the health of the educated: An examination of whether social change would save more lives than medical advances. Am J Public Health 2007;97:679-83.

13. Montez JK, Hummer RA, Hayward MD. Educational attainment and adult mortality in the United States: A systematic analysis of functional form. Demography 2012;49:315-36.

14. Smith GD, Neaton JD, Wentworth D, Stamler R, Stamler J. Socioeconomic differentials in mortality risk among men screened for the Multiple Risk Factor Intervention Trial: I. White men. Am J Public Health 1996;86:486-96.
15. Cohen DA, McKenzie TL, Sehgal A, Williamson S, Golinelli D, Lurie N. Contribution of public parks to physical activity. Am J Public Health 2007;97: 509-14.

16. Lee RE, Heinrich KM, Reese-Smith JY, Regan GR, Adamus-Leach HJ. Obesogenic and youth oriented restaurant marketing in public housing neighborhoods. Am J Health Behav 2014;38:218-24.

17. Romieu I, Gouveia N, Cifuentes LA. Multicity Study of Air Pollution and Mortality in Latin America. Boston, MA: Health Effects Institute; 2010.

18. Harrell E, Langton L, Berzofsky M, Couzens L, Smiley-McDonald H. 2014. Household poverty and nonfatal violent victimization, 2008-2012. Bur Justice Stat November Accessed September 11, 2015.

19. Cummins S, Curtis S, Diez-Roux AV, Macintyre S. Understanding and representing 'place' in health research: A relational approach. Soc Sci Med 2007;65: 1825-38.

20. Krieger N, Chen JT, Waterman PD, Rehkopf DH, Subramanian SV. Race/ethnicity, gender, and monitoring socioeconomic gradients in health: A comparison of area-based socioeconomic measuresThe public health disparities geocoding project. Am J Public Health 2003;93:1655-71.

21. Jones K, Duncan C. Individuals and their ecologies: Analysing the geography of chronic illness within a multilevel modelling framework. Health Place 1995; 1:27-40.

22. Carter P, Cook LJ, Macy ML, et al. Individual and neighborhood characteristics of children seeking emergency department care for firearm injuries within the PECARN network. Acad Emerg Med April 2017;24:803-13.

23. van Vuuren CL, Reijneveld SA, van der Wal MF, Verhoeff AP. Neighborhood socioeconomic deprivation characteristics in child (0-18 years) health studies: A review. Health Place 2014;29:34-42.

24. Bradley EH, Elkins BR, Herrin J, Elbel B. Health and social services expenditures: Associations with health outcomes. BMJ Qual Saf 2011;20:826-31.

25. Chetty R, Hendren N. The impacts of neighborhoods on intergenerational mobility II: County-level estimates. National Bureau of Economic Research; 2016. Available from: http://www.nber.org/papers/ w23002. Accessed May 5, 2017.

26. Lagerlund M, Merlo J, Vicente RP, Zackrisson S. In: Dalal K, ed. Does the neighborhood area of residence influence non-attendance in an urban mammography screening program? A multilevel study in a Swedish city. PLoS One 2015;10(10):e0140244.

27. Meshefedjian GA, Ouimet MJ, Frigault LR, Leaune V, Ait Kaci Azzou S, Simoneau ME. Association of material deprivation status, access to health care services, and lifestyle with screening and prevention of disease, Montreal, Canada, 2012. Prev Chronic Dis 2016;13:E137. 
28. Lo SH, Halloran S, Snowball J, Seaman H, Wardle J, von Wagner C. Colorectal cancer screening uptake over three biennial invitation rounds in the English bowel cancer screening programme. Gut 2015;64:282-91.

29. Centers for Medicare \& Medicaid Innovation. Accountable Health Communities Model. August 17, 2017. Available from: https://innovation.cms.gov/ initiatives/ahcm/. Accessed August 18, 2017.

30. Centers for Medicare \& Medicaid Services. New hospitals and health care providers join successful, cutting-edge federal initiative that cuts costs and puts patients at the center of their care. January 11, 2016. Available from: http://www.hhs.gov/about/ news/2016/01/11/new-hospitals-and-health-careproviders-join-successful-cutting-edge-federalinitiative.html. Accessed January 27, 2016.

31. Assistant Secretary for Planning and Evaluation. Social risk factors and performance under medicare's value-based purchasing programs. 2016. Available from: https://aspe.hhs.gov/system/files/pdf/ 253971/ASPESESRTCfull.pdf.

32. Westfall J. Cold-spotting: Linking primary care and public health to create communities of solution. J Am Board Fam Med 2013;26:239-40.

33. Mellnik T. Top 100 counties-Median household income, 2011. The Washington Post. September 20, 2012. Available from: http://www.washingtonpost. com/wp-srv/special/local/highest-income-counties/. Accessed July 29, 2017.

34. Butler DC, Petterson S, Phillips RL, Bazemore AW. Measures of social deprivation that predict health care access and need within a rational area of primary care service delivery. Health Serv Res 2013;48(2 Pt 1):539-59.

35. Mueller G, Berger K. The influence of neighbourhood deprivation on the prevalence of diabetes in 25- to 74-year-old individuals: First results from the dortmund health study. Diabet Med 2012;29:831-3.

36. Mezuk B, Chaikiat A, Li X, Sundquist J, Kendler KS, Sundquist K. Depression, neighborhood deprivation and risk of type 2 diabetes. Health Place 2013;23: 63-9.

37. Ford PB, Dzewaltowski DA. Neighborhood deprivation, supermarket availability, and BMI in lowincome women: A multilevel analysis. J Community Health 2011;36:785-96.

38. Powell-Wiley TM, Ayers C, Agyemang P, et al. Neighborhood-level socioeconomic deprivation predicts weight gain in a multi-ethnic population: Longitudinal data from the Dallas Heart Study. Prev Med 2014;66:22-7.

39. Pearson AL, Bentham G, Day P, Kingham S. Associations between neighbourhood environmental characteristics and obesity and related behaviours among adult New Zealanders. BMC Public Health 2014;14:553.

40. Shih M, Dumke KA, Goran MI, Simon PA. The association between community-level economic hardship and childhood obesity prevalence in Los Angeles. Pediatr Obes 2013;8:411-7.

41. Rossen LM. Neighbourhood economic deprivation explains racial/ethnic disparities in overweight and obesity among children and adolescents in the USA. J Epidemiol Community Health 2014;68:123-9.

42. Tong ST, Liaw WR, Kashiri PL, et al. Clinician experiences with screening for social needs in primary care. J Am Board Fam Med 2018:31:351-363.

43. Gold R, Cottrell E, Bunce A, et al. Developing electronic health record (EHR) strategies related to health center patients' social determinants of health. J Am Board Fam Med 2017;30:428-47.

44. Lindau ST, Makelarski J, Abramsohn E, et al. CommunityRx: A population health improvement innovation that connects clinics to communities. Health Aff (Millwood) 2016;35:2020-9.

45. Sandberg SF, Erikson C, Owen R, et al. Hennepin Health: A safety-net accountable care organization for the expanded medicaid population. Health Aff (Millwood) 2014;33:1975-84. 